\title{
Chitosan Molecular Weight Effects on The Synthesis of Gold Nanoparticles and Catalytic Degradation of Environmental Pollutants
}

\author{
Hosam I. Salaheldin ${ }^{1,2^{*}}$ \\ ${ }^{1}$ Department of Physics, Faculty of Science, Mansoura University, El-Gomhorya Street, 35516 Mansoura, Egypt \\ ${ }^{2}$ Department of Physics, Faculty of Applied Science, Umm Al-Qura University, Makkah 21955, PO Box 715, \\ Kingdom of Saudi Arabia \\ *dr.hosamibrahim@gmail.com
}

\begin{abstract}
Gold nanoparticles (Au NPs) was synthesized with Chitosan different molecular weight (MW) using a microwave as a heating source. Since, Chitosan acts as a reducing and stabilizing agent. The as-synthesized Au NPs were characterized by transmission electron microscopy (TEM) images and selected area electron diffraction patterns (SAED). Furthermore, the Au NPs fabrication was ascertained by UV-Visible spectroscopy (UV-Vis) through the detection of the localized surface plasmon resonance (LSPR) characteristic peak, X-ray powder diffraction (XRD), and energy dispersive X-Ray Spectroscopy (EDS). The formation of the Au NPs was confirmed by the detection of a LSPR peak at 518-527 nm in the UV-Vis spectrum. In addition, the XRD studies depicted that the obtained Au NPs were highly crystalline with 'face-centered' cubic geometry. Moreover, TEM micrographs showed that the most Monodispersed AuNPs was synthesized with low molecular weight (LMW) Chitosan with particle size $4.48 \pm 0.09 \mathrm{~nm}$. The synthesized Chitosan-Au nanocomposite exhibited an efficient catalytic property in the reduction of two organic environmental pollutants which are, 4nitrophenol (4-NP) and methyl orange (MO) dye in the presence of sodium borohydride $\left(\mathrm{NaBH}_{4}\right)$.
\end{abstract}

Keywords: Gold nanoparticles, Chitosan molecular weight, catalytic degradation, 4-nitrophenol, Methyl orange.

Language: English

Date of Publication: 31-05-2018

DOI: 10.24297/jap.v14i2.7347

ISSN: 2347-3487

Volume: 14 Issue: 2

Journal: Journal of Advances in Physics

Website: https://cirworld.com

This work is licensed under a Creative Commons Attribution 4.0 International License. 


\section{INTRODUCTION}

Many aromatic compounds, such as dyes and phenols, are released from industrial processes. Since, they are among the main causes that responsible for the severe environment contamination for either soil and surface water. Dyes pollutants are produced from printing, dying, dyestuff manufacturing, plastics, food, drugs, cosmetics, and textile industries. The effuents products released from these industries are accompanied by toxic, poor biodegradability characteristics. Azo dyes, a synthetic aromatic compound with one or more of an Azo group $(-\mathrm{N}=\mathrm{N})$, comprise more than half of the world dye pollutants [1]. These Azo-dyes are identified with either of carcinogenic and/or genotoxic agents. There are many examples of azo dyes such as Congo red, Amaranth, Orange G, and Methyl Orange (MO). Moreover, they are considered one of the most colorized environmental pollutants of water, therefore, the dye removal or degradation of the water waste is a tremendous goal. Also, phenol and its derivatives are being nitroaromatics compounds that are toxic and harmful to living organisms even at low concentrations. It was reported that phenol and its derivatives have serious adverse effects on human being's health, including kidney, pancreas, liver damage. In addition, the body protein degeneration, skin and eye irritation, tissue erosion, anaemia, high blood pressure, and central nervous system paralysis [2]. Furthermore, 4-nitrophenol (4-NP) is one of the most famous nitrophenolic compounds where it is toxic, anthropogenic, micrppollutant, and inhibitory in nature. The removal or degradation of these pollutants can be achieved by several methods such as biological biosorption $[3,4]$, enzymatic microbial process via bacteria $[5,6]$, Fenton like process $[7,8]$, photocatalysis [9-11], ozonation $[12$, 13], and reductive degradation [14-16]. In order to remove complex dye these organic compounds from the water waste, the microscale nanoparticles (NPs) such as silver [17, 18], gold [19, 20], zinc oxide [21], and titanium oxide [22] were used. Natural polymers such as starch, cellulose, gelatin, chitin, can be widely used as an adequate matrix for the synthesized nanoparticles. Where, Chitosan, is a structural biopolymer of highly hydrophobic polyssacrides that basically consisting of chitin. Since, chitin is an ordered crystalline microfibrils, that can be extracted from useless products of the shrimp, crab, and squid [23-25]. Due to their non-toxic nature, bioactive, biocompatible, and biodegradable properties, Chitosan has a wide attractive range of NPs, pharmaceutical, antibacterial, antifungal, and medical applications. Microwave, a simple and cheap, efficient heat radiation source, supplys different precursor salts with the required heat energy to synthesis NPs. Since, it is known that energy is among competent heat routes to fabricate NPs. Therefore, microwave heat radiation is responsible for driving the chemical reaction in an aqueous medium with (i) a high dipole moment, and (ii) rapid volumetric heating. Then, a uniform and quick energy may be transferred into the reaction medium. This could be achieved through supplying the reaction solution with different wavelengths from microwave radiation heat [26-29]. The main objective of this work is to study the efficacy of the catalytic activity of the synthesized AuNPs towards a two organic toxic pollutants that are 4-NP and MO. This was carried out using Chitosan different MW (i.e., HMW, MMW, LMW) via simple microwave heating irradiation method. Since, Chitosan (a non toxic, natural, and biodegradable polymer) was used as a reducing and capping agent. Furthermore, to obtain a nearly monodispersed AuNPs, various experimental synthesis conditions were studied such as $\mathrm{HAuCl}_{4}$ salt molar concentration, irradiation time, and microwave radiation power.

\section{MATERIALS AND EXPERIMENTAL WORK}

\subsection{MATERIALS}

Chitosan powder with high molecular weight of $370,000-310,000 \mathrm{kDa}$ and deacylyaltion degree (DD) $>70 \%$, whereas medium and low molecular weight of 310,000-190,000 kDa (DD 70-80\%) and 50,000-190,000 kDa (DD < 80\%) were supplied from Sigma Aldrich. Also, gold tetrachlororauric acid $\left(\mathrm{HAuCl}_{4} \cdot 3 \mathrm{H}_{2} \mathrm{O}\right)$ and sodium borohydride $\left(\mathrm{NaBH}_{4}\right)$ were purchased from Sigma Aldrich (United States). Methyl orange $\left(\mathrm{C}_{14} \mathrm{H}_{14} \mathrm{~N}_{3} \mathrm{NaO}_{3} \mathrm{~S}\right)$ was supplied by Hopkins \& William Chemicals (United States), while 4-nitrophenol (4-NP) was supplied by Merck (United States). All materials were used as purchased, without further purification. 


\subsection{Synthesis of AuNPs}

In a typical experiment, $0.2 \mathrm{~g}$ of Chitosan were dissolved in $20 \mathrm{~mL} 1 \%$ acetic acid under vigorous stirring on a magnetic stirrer for about $3 \mathrm{hrs}$ at $40^{\circ} \mathrm{C}$. Since High, medium, and low Chitosan MW were abbreviated as HMW, MMW, and LMW Chitosan, respectively. The effect of different experimental conditions of the synthesis of Au NPs, such as various molar concentrations of $\mathrm{HAuCl}_{4}$, microwave irradiation time, and microwave power was demonstrated. Therefore, in order to investigate the effect of the precursor $\mathrm{HAuCl}_{4}$ salt different molar concentrations $(0.5,1.0,1.5,2.0$, and $2.5 \mathrm{mM})$, about $5.0 \mathrm{~mL}$ of $\mathrm{HAuCl}_{4}$ solution, was added drop by drop using a pipette to $20 \mathrm{~mL}$ HMW Chitosan to ensure complete dissolving of the reactants. Then, the colloidal mixture was transferred to a boiling vessel and exposed for $3 \mathrm{~min}$ irradiation time and $1000 \mathrm{~W}$ microwave irradiation power as proposed in the schematic drawing in Fig. 1 . The effect of microwave irradiation time and power on the synthesis of Au NPs, the colloidal solution was irradiated for different intervals (60, 90, 120, 150, and $180 \mathrm{~s}$ ) and various microwave power $(450,600,800,900$, and $1000 \mathrm{~W})$ was tested for the appropriate HMW Chitosan solution. Therefore, the optimum experimental reaction conditions were defined. Later, the same procedure will be applied for both MMW, and LMW Chitosan- $\mathrm{HAuCl}_{4}$ colloidal solution, respectively.

\subsection{Catalytic activity of AuNPs for 4-NP reduction in the presence of $\mathrm{NaBH}_{4}$}

The catalytic activity test of Au NPs for 4-NP reduction was performed as follows: $2.0 \mathrm{~mL}$ of $0.08 \mathrm{mM}$ stock solution of 4-NP, $0.5 \mathrm{~mL}$ of $0.08 \mathrm{M}$ freshly prepared $\mathrm{NaBH}_{4}$ solution in ice-cold water under continuous stirring and $0.3 \mathrm{~mL}$ of Au-Chitosan nanocomposite were mixed in a $3 \mathrm{~mL}$ standard quartz cuvette. Since, the catalytic activity of different gold Chitosan $\mathrm{MW}_{\mathrm{t}}$ was studied, where the colloidal solution concentration of HMW, MMW, LMW Chitosan capped Au NPs was $1.5 \mathrm{mM}, 2.0 \mathrm{mM}$, and $1.5 \mathrm{mM}(1 \%$, w/v), respectively. To monitor the reduction of 4-NP, UV-Vis spectra of the samples at room temperature $\left(25^{\circ} \mathrm{C} \pm 2^{\circ} \mathrm{C}\right)$ were recorded in the range of 200-700 $\mathrm{nm}$. The reaction rate constant $(\mathrm{k})$ of catalytic reactions was estimated through measuring the absorbance decrease at $400 \mathrm{~nm}$.

\subsection{Catalytic activities of AuNPs for methyl orange reduction in the presence of $\mathbf{N a B H}_{4}$}

The catalytic activity of the synthesized Au NPs was investigated by degrading a hazardous dye, Methyl orange with the help of $\mathrm{NaBH} 4$. In general, $20 \mathrm{mg}$ of the dye was added to $1.0 \mathrm{~L}$ of distilled water and used as a stock solution of $0.06 \mathrm{mM}$. After that, $2.0 \mathrm{~mL}$ of the prepared Methyl orange dye was added $0.5(0.06 \mathrm{M})$ of ice-cold fresh prepared NaBH4. Thereafter, about $0.03 \mathrm{~mL}$ of the synthesized Au NPs stabilized with Chitosan was added to the previous mixture solution and mixed in a quartz cuvette of $1 \mathrm{~cm}$ path length ultrasonically for $15 \mathrm{~min}$. Thereby, the rates of degradation of $\mathrm{MO}$ dye in the presence $\mathrm{NaBH} 4$ using Au NPs have been analyzed spectrophototometrically at wavelength $464 \mathrm{~nm}$ with constant time intervals (i.e., every $60 \mathrm{~s}$ ). A control set was maintained without Au NPs for the dye and estimated for the absorbance. This was carried out for different, gold Chitosan MW as mentioned in the 4-NP catalytic activity procedure.

\subsection{Characterization Techniques}

UV-Visible (UV/Vis) Spectrophotometer (Thermo Scientific Evolution 201) with matching quartz cells of $1 \mathrm{~cm}$ was used during all measurements and scanning a wavelength range from 300 to $900 \mathrm{~nm}$. The surface morphology of the nanocomposite was analyzed using a high-resolution transmission electron microscope (HRTEM) and selected area electron diffraction angle (SAED) JEOL JEM-2100 microscope, operating at $200 \mathrm{kV}$. The synthesized $\mathrm{Au}$ nanostructure were characterized using XRD (PANalytical X'Pert PRO powder diffractometer with CuK $\alpha(\lambda=1.5418 \AA$ ). The chemical composition of the products was determined by energy dispersive $x$-ray spectroscopy (EDS) using a JEOL scanning electron microscope (SEM) model JSM 6510 LV instrument that supplied with Oxford X-Max 20. A household microwave (Samsung model MW1030WA, Korea) with a fixed frequency of $2.5 \mathrm{GHz}$ and $1000 \mathrm{~W}$ power was used as an irradiation source. 


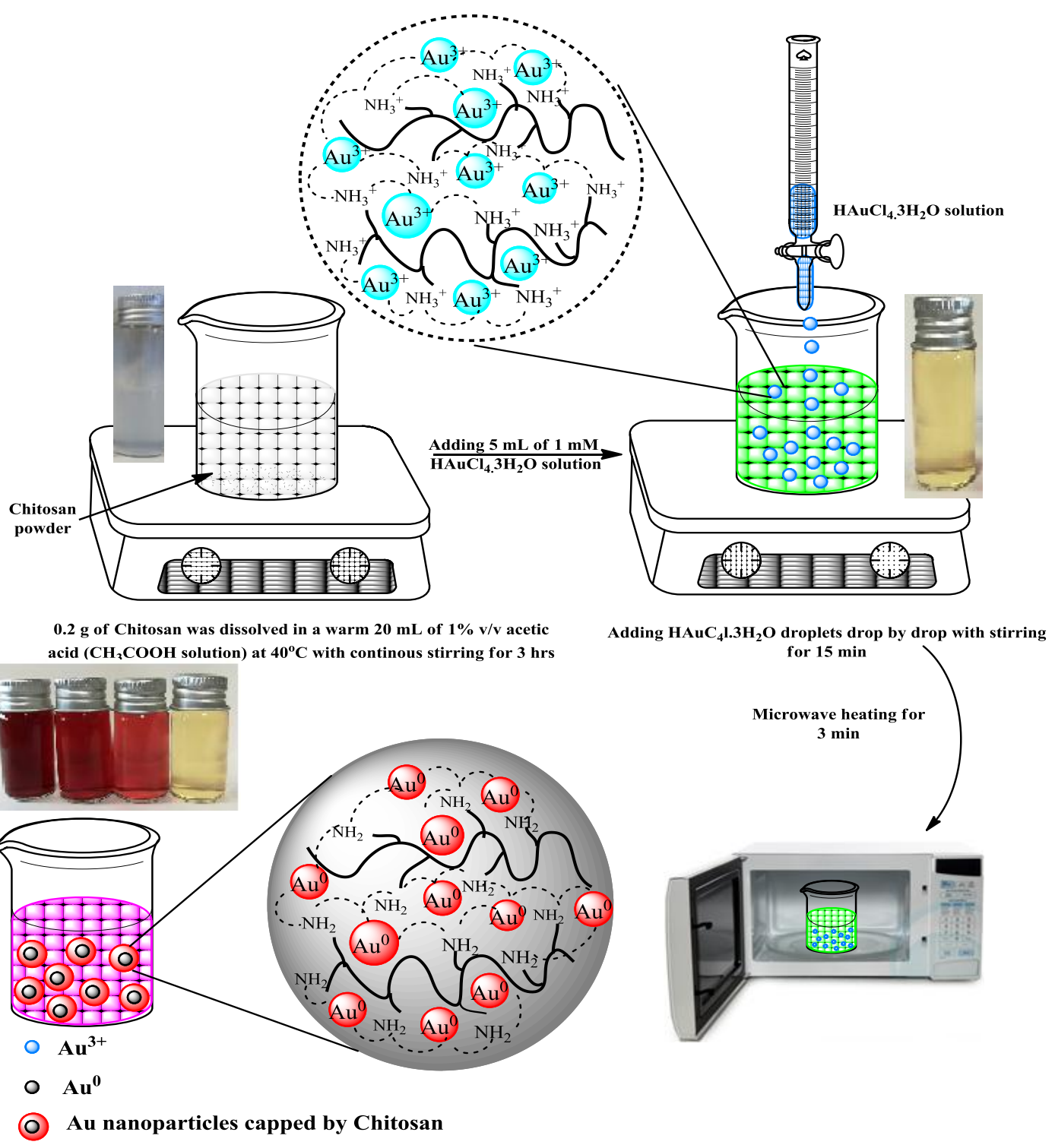

Fig. 1 Schematic drawing of Chitosan-Au nanocomposite synthesis procedure.

\section{RESULTS AND DISCUSSIONS}

\subsection{UV-visible (UV-Vis) spectroscopy analysis}

UV-Vis spectroscopy is a valuable tool used for studying, identifying, and characterizing of metallic NPs. Since, NPs made from certain metals, such as gold and silver, strongly interact with specific wavelengths of light and the proper unique optical characteristics of these materials are the basis for the field of plasmonics. In which, these NPs have vast optical properties which are so sensitive to shape, size, concentration, agglomeration state, and refractive index near the NPs surface according to the most popular form of Mie's theory for spherical NPs within quasi-static limit is given as

$$
C_{e x t}=\frac{24 \pi^{2} R^{3} \varepsilon_{m}{ }^{3 / 2}}{\lambda} \cdot \frac{\varepsilon_{2}}{\left(\varepsilon_{1}+2 \varepsilon_{m}\right)^{2}+\varepsilon_{2}{ }^{2}}
$$

where $C_{\text {ext }}$ is the extinction cross section of the spheres, $R$ is the radius of a homogeneous sphere $\varepsilon_{m}$ is the dielectric constant of the surrounding medium, $\lambda$ is the wavelength of the radiation, and $\varepsilon_{1}$ and $\varepsilon_{2}$ denote the real and imaginary part of the complex dielectric function of the particle material, respectively. A resonance occurs whenever the condition of $\varepsilon_{1}=2 \varepsilon_{\mathrm{m}}$ is satisfied, which explains the dependence of the localized surface 
plasmon resonance (LSPR) extinction peak on the surrounding dielectric environment. For a small $\mathrm{Au}$ nanosphere within the quasi-static limit, its LSPR has an almost fixed resonance frequency and shows limited tenability [30]. In this study, the attempt to synthesize the nanometer gold using microwave irradiation method was carried out. Since, the effect of various variables such as $\mathrm{Au}^{+}$precursor concentration, microwave irradiation time, and power on the Au NPs was investigated. Figure. 2 shows the growth of the LSPR of different concentration of $\mathrm{HAuCl}_{4} .3 \mathrm{H}_{2} \mathrm{O}(0.5,1.0,1.5,2.0$, and $2.5 \mathrm{mM})$. This could be ascertained by the enhancement of the LSPR peak at certain wavelength $\left(\lambda_{\max }=523 \mathrm{~nm}\right)$ as shown in Fig. 2. Also, the increase of absorption peak intensity is related to the increase of $\mathrm{Au}^{3+}$ concentration in the Chitosan/[AuCl $\left.]_{4}\right]^{-}$colloidal solution [31]. Moreover, the change of mixture color which was pale yellow into a red color ( Fig. 2 inset), ensures the formation of Au NPs. This could be attributed to the reduction of the metal salt mechanism which was suggested by Huang and Yang (2004) [32]. Since, they proposed that the Chitosan, a derivative of glucose, which acts as a reducing agent. This could be carried out by the hydroxyl $(-\mathrm{OH})$, and amine $\left(-\mathrm{NH}_{2}\right)$ groups simultaneously [33]. Furthermore, it is suggested that the number of the reducing sugars could be enhanced by the elevated temperature during the microwave irradiation. Moreover, after the reduction of gold ions $\left(\mathrm{Au}^{3+}\right)$ to gold nanoparticles $\left(\mathrm{Au}^{0}\right)$, they were capped by $-\mathrm{NH}_{2}$ and/or $-\mathrm{OH}$ functional groups as proposed in Fig.1. To investigate the effect of the microwave irradiation time on the fabrication of Au NPs, a solution of $20 \mathrm{~mL} \mathrm{HMW}$ Chitosan $(1 \%, w / v)$ mixed $5 \mathrm{~mL}(1.5 \mathrm{mM})$ gold chloride solution was chosen. This is due to, the UV-Vis spectrum of the aforementioned reaction mixture characterized with a narrow full width at half maximum (FWHM) which was $112 \mathrm{~nm}\left(\lambda_{\max }=523 \mathrm{~nm}\right)$ which is attributed to the particle size [27, 34].

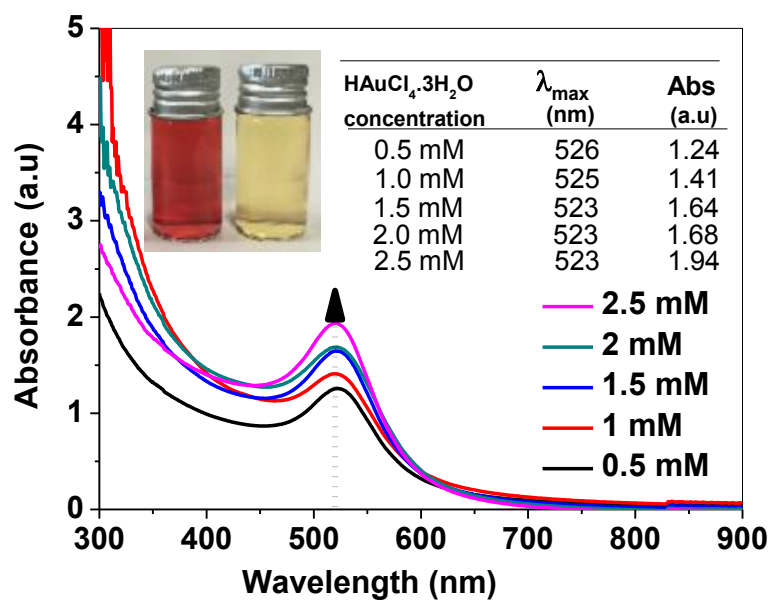

\section{Fig. 2 UV-Vis spectra of Au NPs capped by HMW Chitosan $(20 \mathrm{~mL}, 1 \%$, w/v) along with $(5 \mathrm{~mL})$ different concentration of $\mathrm{HAuCl}_{4}(0.5,1.0,1.5,2.0$, and $2.5 \mathrm{mM})$.}

Since, the narrow FWHM, the smaller the particle size diameter. Figure. 3 represents the UV-Vis absorption spectra of the Chitosan/ $\mathrm{HAuCl}_{4} .3 \mathrm{H}_{2} \mathrm{O}(1.5 \mathrm{mM})$ colloidal solution at different irradiation time $(60,90,120,150$, and $180 \mathrm{~s}$ ). It can be observed the gradual increase of the absorption intensity of LSPR $\left(\lambda_{\max } \simeq 526 \mathrm{~nm}\right)$ for the sample irradiation time (i.e., from 60 to $90 \mathrm{~s}$ ). Whereas, a detected blue shift of the LSPR peak was estimated for 120 and $180 \mathrm{~s}$ irradiation to a shorter wavelength $\left(\lambda_{\max }=523 \mathrm{~nm}\right)$. This could be correlated with the smallest particle size fabrication [35]. Finally, to assess the effect of microwave irradiation power on the Au NPs synthesis, the Chitosan- $\mathrm{HAuCl}_{4}$ colloidal solution was exposed to microwave with power $450,600,800,900$, and $1000 \mathrm{~W}$, respectively. Therefore, $5 \mathrm{~mL}$ of $\mathrm{HAuCl}_{4} .3 \mathrm{H}_{2} \mathrm{O}(1.5 \mathrm{mM})$ was mixed with $20 \mathrm{~mL}$ Chitosan $(1 \%, \mathrm{w} / \mathrm{v})$ and irradiated for $180 \mathrm{~s}$ for different microwave irradiation power. Fig. 4 depicts the UV-Vis absorption spectra and reveals that the gradual increase of absorption intensity at LSPR about $523 \mathrm{~nm}$. Since, it seems that the higher reaction radiation power resulted in an increase in the absorption peak, with increasing the microwave power. This results proposed that the growth of the Au NPs was enriched with the increase of microwave radiation power $[18,29]$. Hence, the obtained data confirm that the optimum reaction conditions for generating the Au NPs was $180 \mathrm{~s}$ microwave irradiation time, and $1000 \mathrm{~W}$ irradiation power. This is in contrast 
to the findings obtained by Ngo et al, (2016) [30], where they found that the Au NPs synthesized with short irradiation time and low irradiation power of the microwave. Since, it was investigated that both the higher microwave power during the ramping regions of the applied microwave power and the longer irradiation time (i.e., retention time of microwave $\simeq 5 \mathrm{~min}$ ) were the optimum synthesis conditions for Au NPs.

This could be owing to the faster formation of glucose units residues from Chitosan that accelerates the reduction of $[\mathrm{Au} \mathrm{Cl}]^{-}$ions to form $\mathrm{Au}^{0}$ nanoparticles. Furthermore, the gradual increase in the absorption peak with with a blue shift for $1.5 \mathrm{mM} \mathrm{HAuCl}_{4}$ concentration $\left(\lambda_{\max }=523 \mathrm{~nm}, 180 \mathrm{~s}\right.$ irradiation time and $1000 \mathrm{~W}$ irradiation power) and more narrower FWHM (Fig. 3 and 4) correlated to the fabrication of small size nanoparticles [30]. This will be confirmed later by transmission electron microscopy micrographs.

The UV-Vis absorption spectra of the gold chloride-MMW Chitosan colloidal solution are depicted in Fig. 5. The solution of different gold chloride colloidal concentration $(5 \mathrm{~mL})$ mixed with $20 \mathrm{~mL}$ MMW Chitosan (1\%, $\mathrm{w} / \mathrm{v}$ ) exhibited the absorption maxima around $527 \mathrm{~nm}$. With the gold chloride concentration increases ( 0.5 to $2.5 \mathrm{mM}$ ), a plasmon absorption peak increased with a remarkable blue shift (from 527 to $520 \mathrm{~nm}$ ) for $2.0 \mathrm{mM}$ $\mathrm{HAuCl}_{4}$ concentration. Moreover, a detected gradual increase in the absorption peak intensity (Fig. 5) confirmed that the fabricated Au NPs with small nanoparticles.

The UV-Vis spectra of LMW Chitosan- $\mathrm{HAuCl}_{4}$ colloidal solutions have been shown in Fig. 6 . Since, the Au NPs spectral peak, of $1.5 \mathrm{mM} \mathrm{HAuCl}_{4}$ exhibited a gradual increase in the absorption peak with a blue shift of LSPR $\left(\lambda_{\max }=518 \mathrm{~nm}\right)$ and narrow FWHM $(110 \mathrm{~nm})$ compared to other $\mathrm{HAuCl}_{4}$ concentrations of 2.0 and $2.5 \mathrm{mM}$ which were 113 and $115 \mathrm{~nm}$, respectively. Therefore, the LMW Chitosan is more proper efficient rather than HMW and MMW Chitosan as reported before [36-38]. Furthermore, this result can be supported by the highest deacetylation degree (DD) value which is approximately more than $75-85 \%$ for LMW Chitosan. Where, the more free amino groups available for gold ion coordination and reduction, the higher yield of reduction [39]. In addition, in comparison with long-chain HMW Chitosan, the short-chain LMW is better in terms of water solubility and biocompatibility [36].

\subsection{X-ray diffraction (XRD) analysis}

Figure.7 represents the XRD patterns of the Au NPs capped by Chitosan different MW, which indicates the formation of gold crystalline structure. Since, the powder XRD patterns peaks at $2 \theta\left(20^{\circ}<\theta<80^{\circ}\right)$ values around $38.42^{\circ}, 44.16^{\circ}, 64.77^{\circ}$, and $77.91^{\circ}$. These $2 \theta$ peak value corresponds to the indexed planes of the crystals (111), (200), (220), and (311), which are in perfect agreement for JCPDS card no.: 04-784 [40]. These major characteristic peaks of Au nanocrystals were attributed to the face centered cubic (FCC) crystalline structure [41]. In addition, according to the low content of Au NPs in the Au-Chitosan bionanocomposite, the diffraction intensity of Au nanocrystal was weak in the pattern. The average particle size of Au NPs can be estimated using Debye-Scherrer equation:

$$
D_{h k l}=K \times \lambda / \beta_{h k l} \times \cos \theta_{h k l}
$$

where $D_{h k l}$ is the particle size perpendicular to the normal line of (hkl) plane, $K$ is the shape factor constant $(K \simeq 0.9), \beta_{\mathrm{hkl}}$ is the width at half height of $(\mathrm{hkl}), \theta_{\mathrm{hkl}}$ is the Bragg angle of (hkl) peak and $\lambda$ is the wavelength of $X$-ray with a value $1.5418 \AA$. From the Scherrer equation, the average crystalline size of Au NPs for Au-HMW, MMW, LMW Chitosan are found $17.25 \pm 3.9,8.9 \pm 2.39$, and $4.71 \pm 1.21 \mathrm{~nm}$, respectively, which are consistent with the findings with the transmission electron microscopy results which will be discussed later. 


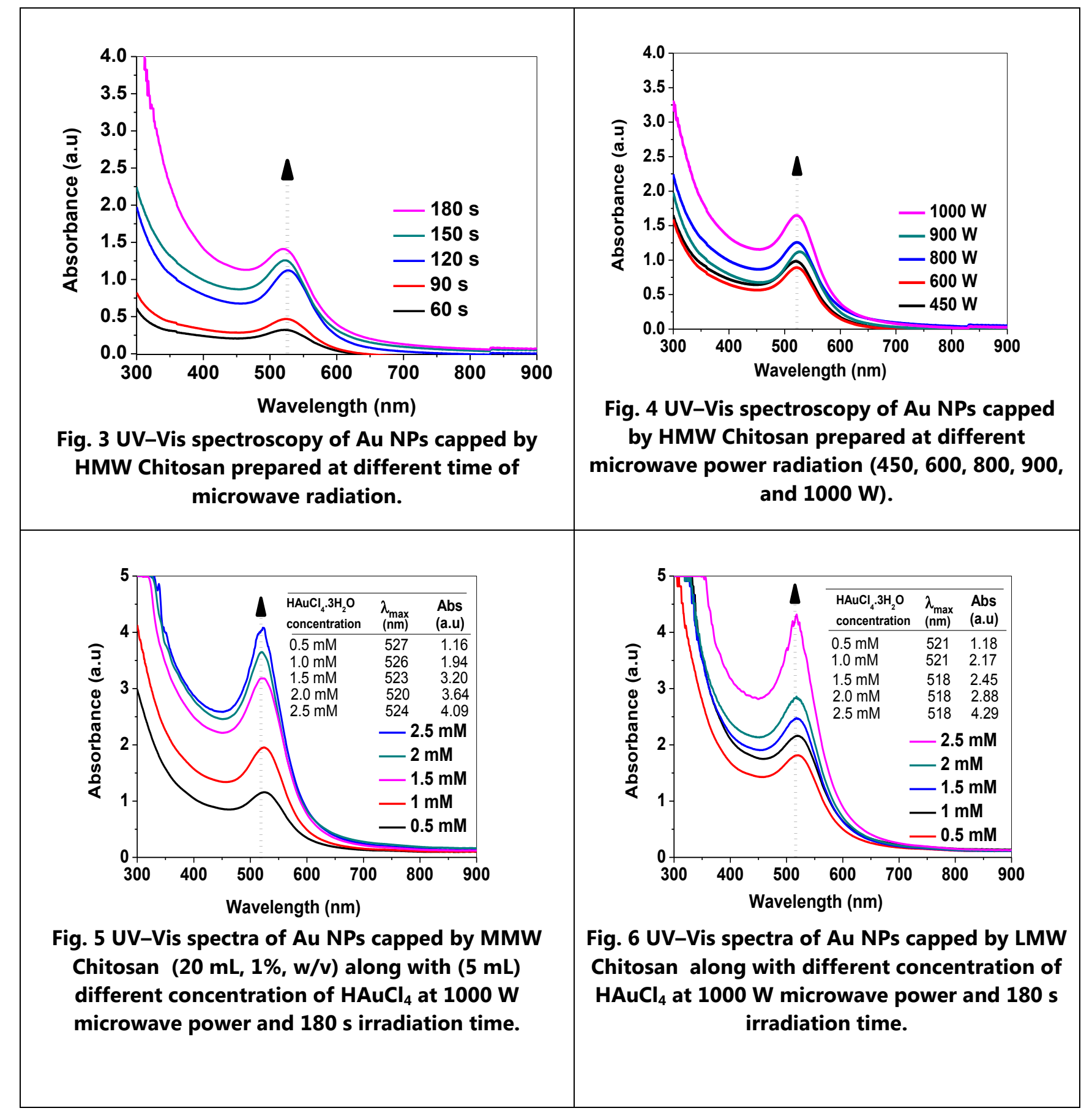




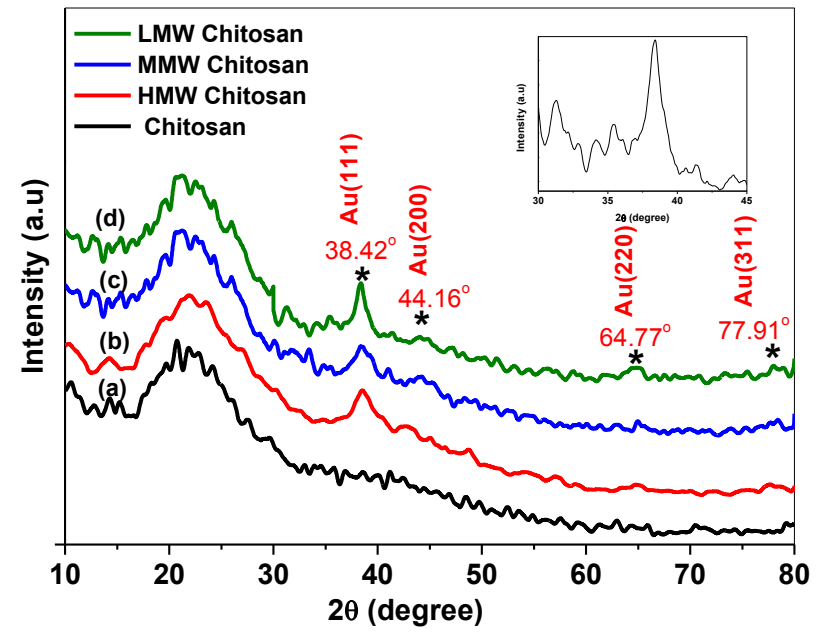

Fig. 7 XRD patterns of (a) Chitosan and the Au NPs synthesized in the presence of (b) HMW (c) MMW, and (d) LMW Chitosan nanocomposites.

\subsection{Transmission electron microscopy (TEM) studies}

The size and morphology of the fabricated Au NPs were investigated using transmission electron microscopy (TEM) analysis. Since, the photographs of Au NPs capped by various Chitosan MW (i.e., HMW, MMW, and LMW ) was revealed that the synthesized NPs were spherical in shape, but with different detected particle size diameter. It can be observed from Fig. 8 of Au NPs capped by a HMW Chitosan TEM image that a polydispersed NPs synthesized with size range 4-18 nm, where nearly more than $70 \%$ of the particles have size between 9-15 nm. Whereas, the size of MMW Chitosan-Au nanocomposite was 5-34 nm. For LMW Chitosan-Au nanocomposite micrograph, it can be noticed that the fabricated NPs of small and narrow particle size $4.48 \pm 0.09 \mathrm{~nm}$. The high resolution TEM (HRTEM) and the nanodiffraction patterns were used to study the morphology and the internal crystalline structure of the synthesized Au NPs stabilized by various types of Chitosan MW. This was carried out using selected-area electron diffraction (SAED) patterns. The typical SAED patterns recorded in the area represented in Fig. 8d, 9d, and 10d are shown in Fig. 8e, 9e, and 10e. Since, they clearly exhibited a bright circular diffraction spots/rings that could indexed to (111), (200), (220), and (311) planes. Since, the spots are predominantly oriented along the (111) plane with a space lattice fringe in the HRTEM image of $2.35 \AA$ and $2.34 \AA$ corresponding to the Au NPs synthesized and stabilized by HMW and MMW Chitosan nanocomposite, as shown in Fig. 8e and 9e, respectively. Whereas, Fig. 10d represents the HRTEM images with clear lattice fringes having a d-spacing of $0.23,0.20$, and $0.14 \mathrm{~nm}$ revealed that the FCC crystal lattice with (111), (200), and (220) planes [42]. Moreover, these findings confirm the results obtained by XRD patterns. In addition, the fast Fourier transformation (FFT) process was used to obtain the Fourier spectra that equivalent to optical diffraction patterns. FFTs were typically employed to recognize the orientation of NPs with respect to the electron beam. The obtained FFT patterns of different Au single crystal synthesized by various Chitosan MW were represented in Figs. 8f, 9f, and 10f. Such FFTs patterns confirmed that the synthesized Au nanocrystal corresponds to FFC crystals [43].

\subsection{Energy Dispersive X-Ray Spectroscopy (EDS) analysis}

EDS is a Microanalysis technique equipped in addition to scanning electron microscopy (SEM) to determine the elemental structure of certain examined samples. The EDS analysis of Au-Chitosan different MW samples nanocrystallites showed an optical absorption band peak at approximately $2.2 \mathrm{keV}$ [44] in the three studied samples as shown in Fig 11a-c. Since, a clear peak for Au atoms was seen in the spot directed EDS spectrum of all the Au NPs samples. In addition, By comparing relative peak sizes it can be concluded that the presence of 
$\mathrm{Au}$ is really detected. Also, The presence of carbon, and oxygen atoms signals were observed, where this is likely to be due to X-ray emission from the Chitosan structure. Furthermore, the elemental mapping analysis of the Au NPs showed a tremendous distribution of metallic Au of the Au NPs pellet solution.
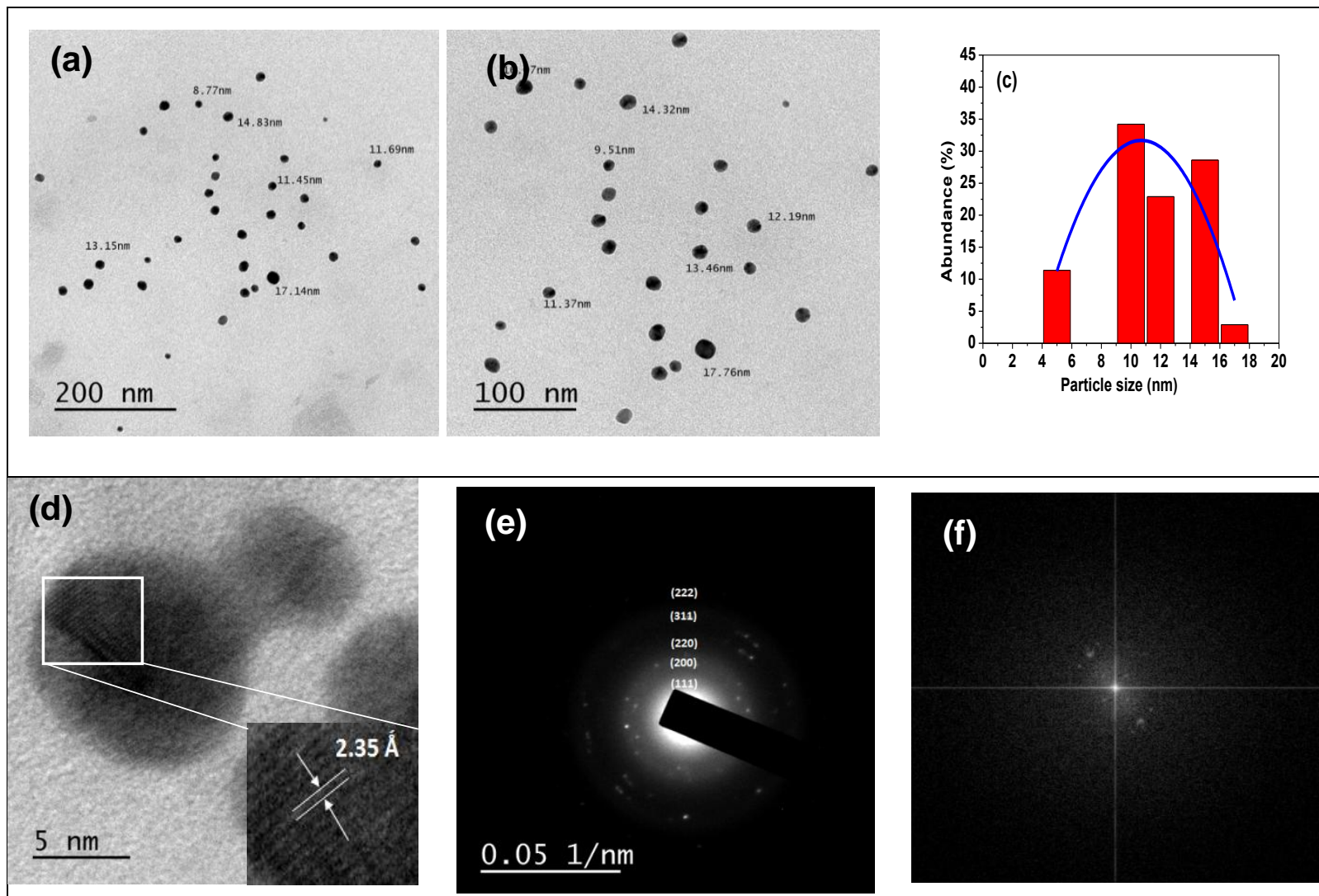

Fig. 8 Typical TEM images of the Au NPs synthesized using HMW Chitosan nanocomposite at different scale bar (a) $200 \mathrm{~nm}$, (b) $100 \mathrm{~nm}$, (c) HRTEM image, (d) the corresponding size distribution histogram (e) the indexed selected-area diffraction pattern on the area (c), and (f) the corresponding characteristic FFT.

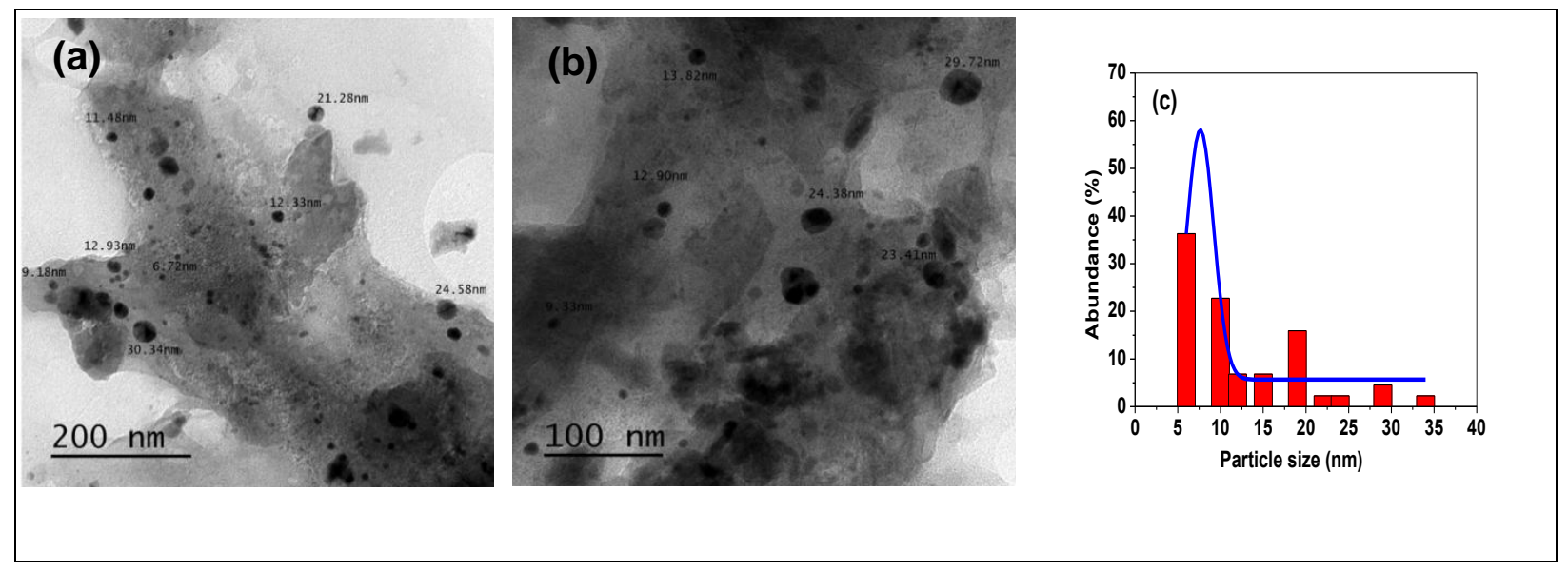




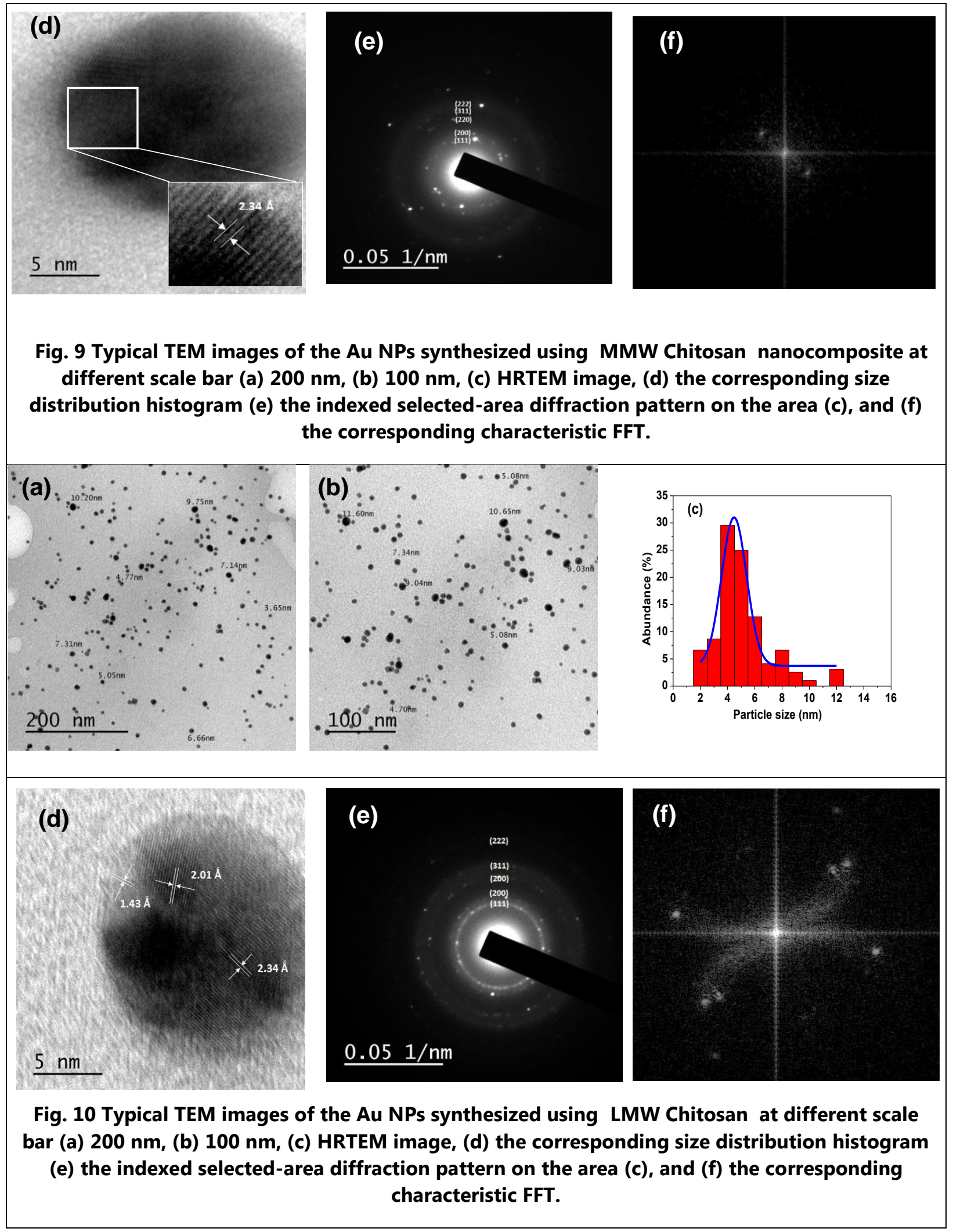




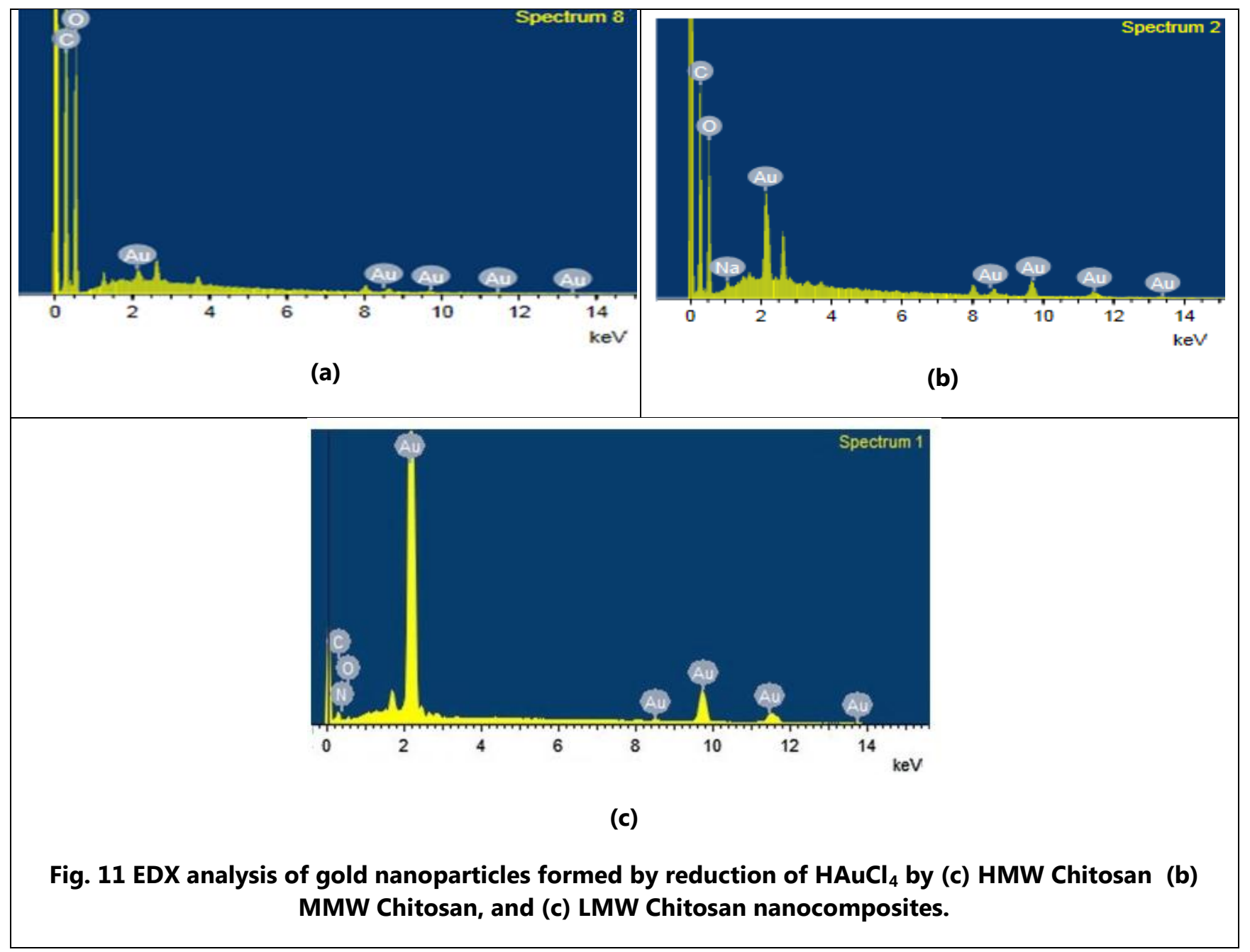

\subsection{Catalytic reduction of 4-nitrophenol in the presence of $\mathrm{NaBH}_{4}$}

The efficacy of the synthesized Au NPs stabilized by different Chitosan MW was evaluated by the catalytic reduction of 4-nitrophenol (NP) into 4-aminophenol (AP) in the presence of sodium borohydride $\left(\mathrm{NaBH}_{4}\right)$. The catalytic degradation of 4-NP to 4-AP was monitored by UV-Vis spectroscopy. Since, the color of 4-NP is light yellow, and exhibits a maximum absorption peak at $\lambda_{\max }=317 \mathrm{~nm}$ as shown in Fig. 12a After then, $\mathrm{NaBH}_{4}$ was added and the color was converted to yellow green with a red-shift of the absorption peak from 317 to 400 $\mathrm{nm}$ (Fig. 12a inset). This is correlated to the formation of 4-nitrophenolate ion. To the reaction mixture, $0.3 \mathrm{~mL}$ of Au NPs stabilized by various Chitosan MW was added. The reaction course was monitored every 60 seconds by tracking the gradual decrease of the absorption spectra at $\lambda_{\max }=400 \mathrm{~nm}$ that attributed to 4nitrophenolate ion, with a noticeable growing a new peak $293 \mathrm{~nm}$ which is ascertained to 4-AP formation as shown in Fig. 12b. The catalytic reduction of the reaction follows the Langmuir-Hinshewood (LH) model [45]. This reaction correlates to the pseudo-first-order kinetics, and the rate constant $(k)$ of the catalytic reaction can be determined using the following relation:

$$
\frac{d C_{t}}{d C_{t}}=k C_{t} \quad \text { or } \quad \ln \left(\frac{C_{t}}{C_{0}}\right)=\ln \left(\frac{A_{t}}{A_{0}}\right)=-k t
$$

Where $\mathrm{C}_{0}$ and $\mathrm{C}_{\mathrm{t}}$ are the concentration of 4-NP at the beginning and the time $t$ of the reaction, while $\mathrm{A}_{0}$ and $\mathrm{A}_{\mathrm{t}}$ are their corresponding absorption, respectively. Figure. $12 \mathrm{c}$ and $12 \mathrm{~d}$ represent the catalytic reduction of 4$\mathrm{Np}$ via MMW and LMW Chitosan-Au nanocomposite with a reduction time 9 and 7 min, respectively. Moreover, the rate constant values obtained using various Au NPs catalysts were represented in table.1. Figure. 12e shows a good linear relationship of $-\ln \left(\frac{A_{t}}{A_{0}}\right)$ versus reaction time t. Upon comparing the catalysis results of the three Au NPs capped by various Chitosan MW, it obviously appears that Au NPs stabilized by 
LMW Chitosan with small particle size $(4.48 \mathrm{~nm})$ exhibit higher catalytic degradation [46]. Whereas, $\mathrm{k}$ deceased to $0.20699 \mathrm{~min}^{-1}$ and $0.25172 \mathrm{~min}^{-1}$ for Au NPs stabilized by HMW and MMW Chitosan, respectively as depicted in the table. 1. This is attributed to the increase in the size of the Au NPs, which were $13.45 \pm 5.58$ and $7.63 \pm 0.79 \mathrm{~nm}$, thus $\mathrm{k}$ values decrease upon raising the Au NPs size. Since, the catalytic reduction carried out on the surface of the catalysts, where $\mathrm{BH}_{4}^{-}$Reacts with Au NPs to form the metal hybrid, then discharging of electrons, $\mathrm{NaBH}_{4}$ ions via the metal acceptor. To complete this reaction, hydrogen ions $\left(\mathrm{H}^{+}\right)$are needed, which can be provided by the $\mathrm{H}_{2} \mathrm{O}$ molecules that act as a polar protic solvent [47].
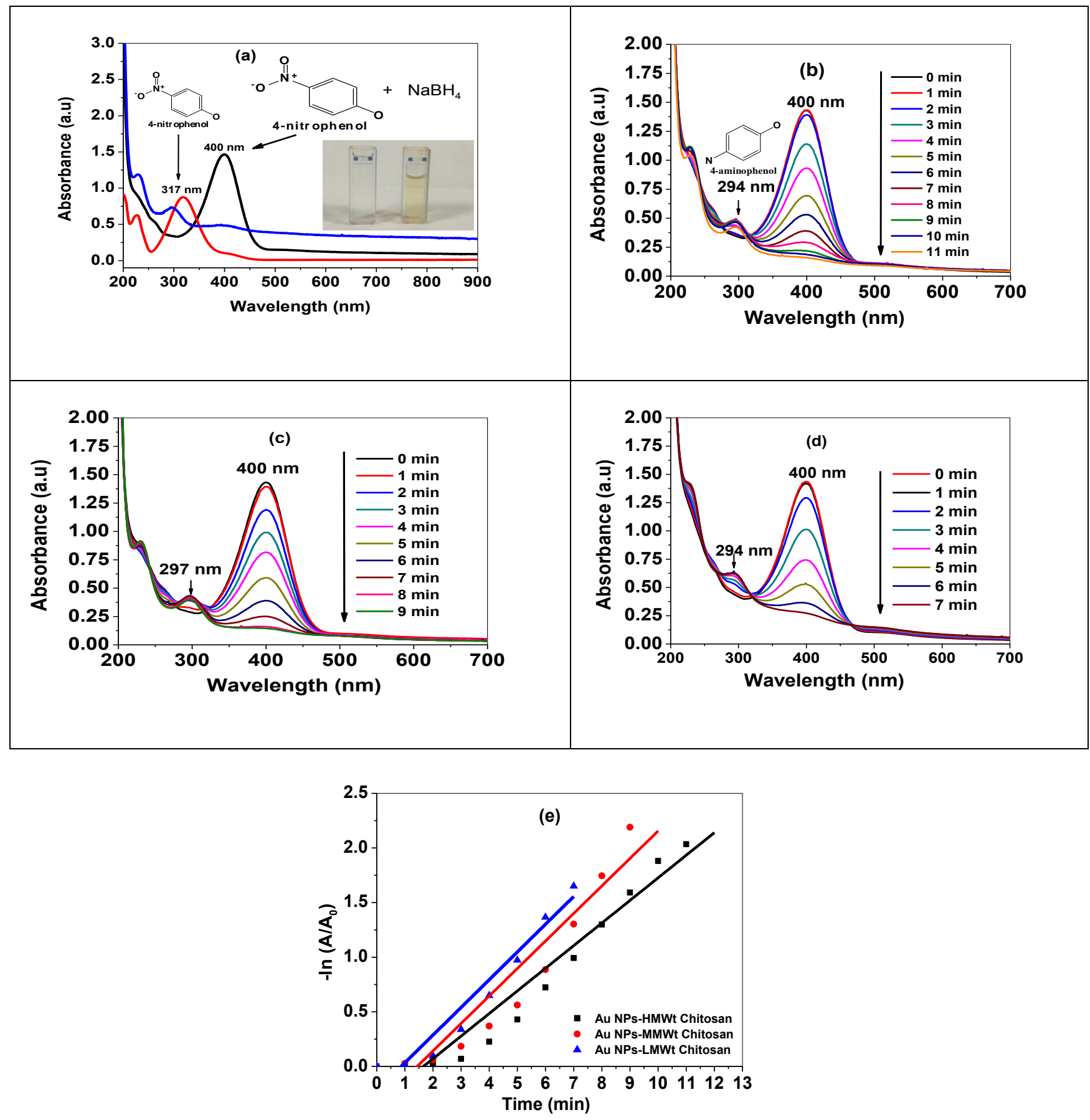

Fig 12. (a) UV-Vis spectra of 4-NP before and after the addition of the NaBH4, (b) -(d) UV-Vis spectra for the reduction analysis of 4-NP using (b) Au NPs/HMW (c) Au NPs/MMW, and (d) Au NPs/LMW Chitosan nanocomposites, and (e) The plot of $\ln \left(A_{t} / A_{0}\right)$ vs time (min). 
Table 1. The rate constant of the kinetic reaction to the reduction of 4-NP with different Au NPs-MW Chitosan nanocomposites catalysts.

\begin{tabular}{|c|c|c|c|}
\hline The catalyst type & $\begin{array}{c}\text { Reaction time } \\
\mathbf{( m i n )}\end{array}$ & $\begin{array}{c}\text { K rate constant } \\
\mathbf{( m i n}^{-\mathbf{1}} \mathbf{)}\end{array}$ & $\begin{array}{c}\text { Correlation } \\
\text { coefficient } \mathbf{R}^{\mathbf{2}} \mathbf{)}\end{array}$ \\
\hline $\begin{array}{c}\text { Au NPs-HMW } \\
\text { Chitosan }\end{array}$ & 11.0 & 0.20699 & 0.95559 \\
\hline $\begin{array}{c}\text { Au NPs-MMW } \\
\text { Chitosan }\end{array}$ & 9.0 & 0.25172 & 0.9273 \\
\hline $\begin{array}{c}\text { Au NPs-LMW } \\
\text { Chitosan }\end{array}$ & 7.0 & 0.25372 & 0.93587 \\
\hline
\end{tabular}

\subsection{Catalytic reduction of methyl orange in the presence of $\mathrm{NaBH}_{4}$}

The $\mathrm{MO}$ dye degradation with the aid of $\mathrm{NaBH}_{4}$ in the absence and presence of Au nanocatalyt was recorded using UV-Vis absorption spectra as shown in Fig. 13a. This catalytic reduction is achieved via Au NPs, which acts as an electron relay and helps in the transfer of electrons from the $\mathrm{BH}^{-}$ions to the dyes. This is followed by a successive degradation of the dye and an observed gradual decrease in the absorption intensity of the UV-Vis spectrum as shown in Fig. 13b. The chemical reduction of $\mathrm{MO}$ by $\mathrm{NaBH}_{4}$ in the presence of Au NPs as catalyst is shown in Fig. $13 \mathrm{~b}$-d for different Chitosan $\mathrm{MW}$-Au nanocatalyst. It is known that $\mathrm{NaBH}_{4}$ individually is unable to reduce methyl orange in the absence of a catalyst, thus showing the catalytic efficacy of Au NPs [48]. From Fig. 13b-d, it is apparent that there is a rapid change in absorbance of $M O$ in the occurrence of Chitosan-Au nanocomposite. The degradation is indicated by the progressive reduction absorption intensity and absorbance at $\mathrm{k}$ of of the UV-Vis spectra. The degradation of MO dye occurs within 8 and 6 min for HMW and MMW Chitosan stabilized Au NPs, respectively, as shown in Figs 13.b and 13.c. Whereas, it is observed that the degradation time for LMW Chitosan-Au nanocatalyst, was 4 min only. This indicates that the rapid catalytic degradation performance of LMW compared HMW and MMW Chitosan capping the synthesized Au NPs. Furthermore, for LMW Chitosan-Au nanocatalyst, the reduction reaction rate $\mathrm{k}$ was found $0.27012 \mathrm{~min}^{-1}$ compared to HMW and MMW Chitosan-Au nanocomposite which were 0.14773 and $0.18667 \mathrm{~min}^{-1}$, respectively as represented in the table. 2 . This result consistent with the catalytic activity efficiency for 4-NP using LMW Chitosan-Au nanocatalyst in the presence of $\mathrm{NaBH}_{4}$. Therefore, one can conclude the Au NPs capped by Chitosan, which acts as both a reducing and a capping agent for gold salt, can be efficiently used as an effective catalytic removal agent for different environmental aromatic pollutants.

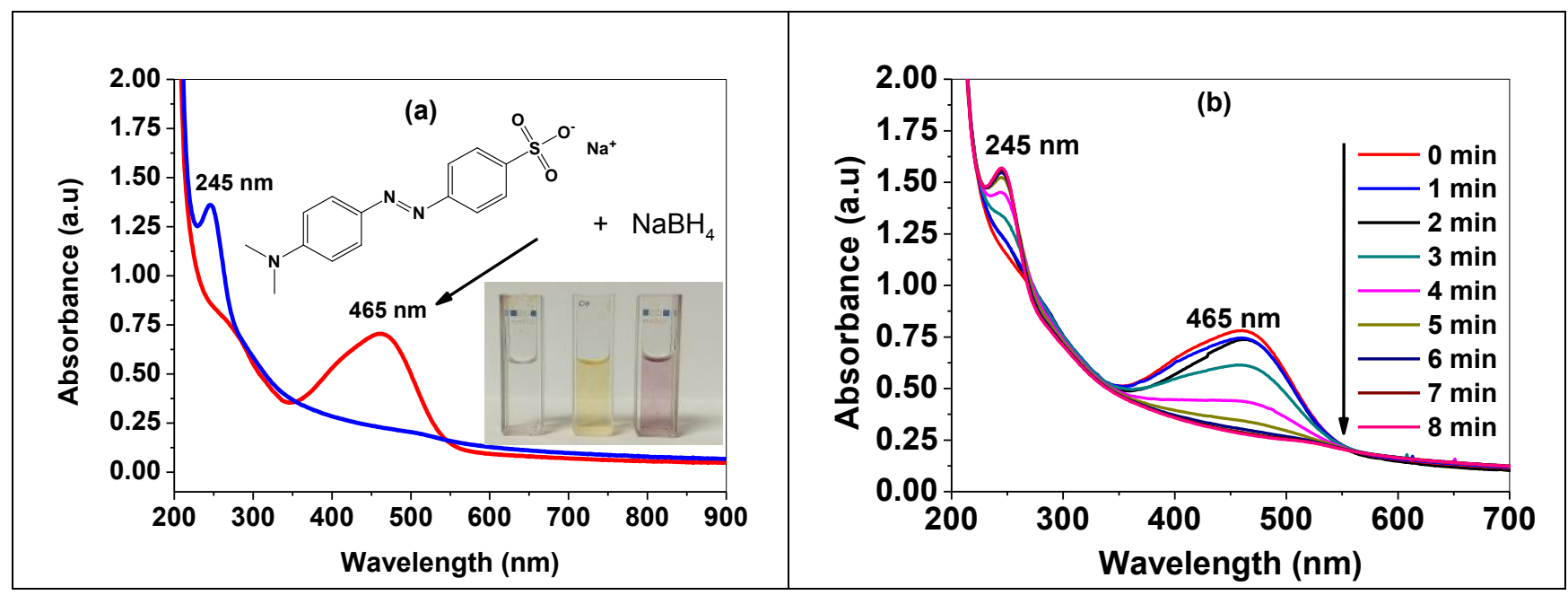




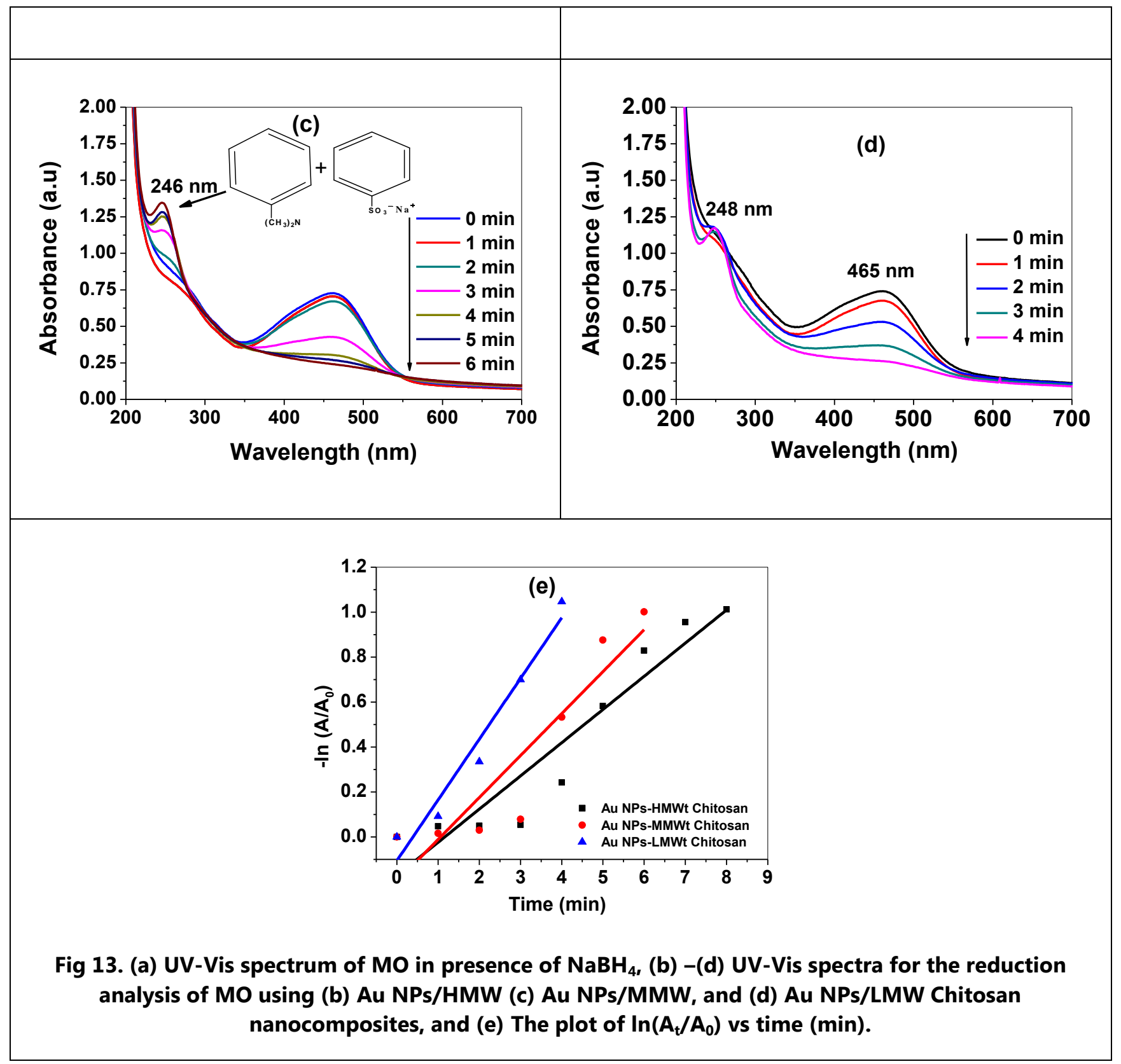

Table 1. The rate constant of the kinetic reaction to the reduction of MO with different Au NPs-MW Chitosan nanocomposites catalysts.

\begin{tabular}{|c|c|c|c|}
\hline The catalyst type & $\begin{array}{c}\text { Reaction time } \\
(\mathbf{m i n})\end{array}$ & $\begin{array}{c}\text { K rate constant } \\
\mathbf{( m i n}^{-\mathbf{1}} \mathbf{)}\end{array}$ & $\begin{array}{c}\text { Correlation } \\
\text { coefficient } \mathbf{( R}^{\mathbf{2}} \mathbf{)}\end{array}$ \\
\hline $\begin{array}{c}\text { Au NPs-HMW } \\
\text { Chitosan }\end{array}$ & 8.0 & 0.14773 & 0.90526 \\
\hline $\begin{array}{c}\text { Au NPs-MMW } \\
\text { Chitosan }\end{array}$ & 6.0 & 0.18667 & 0.82429 \\
\hline $\begin{array}{c}\text { Au NPs-LMW } \\
\text { Chitosan }\end{array}$ & 4.0 & 0.27012 & 0.94494 \\
\hline
\end{tabular}




\section{Conclusions}

In this study, Au NPs were prepared using a green, cost effective, and rapid reduction method, where the microwave was used as a simple heating source. Since, for the synthesis Au NPs, the optimum reduction conditions such as concentrations of $\mathrm{HAuCl}_{4}$, irradiation, and microwave radiation power were investigated. This was carried out using a polymeric matrix of different Chitosan MW (i.e., HMW, MMW, LMW) that used as a reducing and capping agent. TEM micrographs showed that a nearly monodispersed Au NPs with a small particle size diameter $4.48 \pm 0.09 \mathrm{~nm}$ synthesized with LMW Chitosan-Au nanocomposite. Whereas, it was $13.45 \pm 5.58$ and $7.63 \pm 0.79 \mathrm{~nm}$ for HMW and MMW Chitosan -Au nanocomposite, respectively. The rapid degradation of 4-NP and MO aromatic pollutants was carried out with a high reaction rate constant LMW rather than HMW, and MMW Chitosan -Au nanocatalyst. This is due to that the small NPs size enables a high surface to volume ratio for the rapid catalytic degradation. Therefore, Chitosan-Au nanocomposite is strongly suggested as an adequate nanocatalyst for the removal of the environmental aromatic pollutants.

\section{References}

1. Siby Joseph, Beena Mathew. 2015 Microwave-assisted green synthesis of silver nanoparticles and the study on catalytic activity in the degradation of dyes. Journal of Molecular Liquids 204, 184-19.

2. Yehia M. Magdy. Hossam Altaher. E. El Qada. 2018 Removal of three nitrophenols from aqueous solutions by adsorption onto char ash: equilibrium and kinetic modeling. Applied Water Science 8, 1-15.

3. Pearce, C. I., Lioyd, J. R. and Guthrie, J. T. 2003 The removal of colour from textile wastewater using whole bacterial cells: a review. Dyes and pigments $58,179-186$.

4. Deborah Olubunmi Aderibigbe, Abdur-Rahim Adebisi Giwa, Asiata Omotayo Ibrahim and Isah Adewale Bello. 2017 Biosorption of Nitrophenol from Aqueous Mixture of Phenolic Compounds Using Sawdust of Parkia biglobosa. applied science and technology 22(5), 1-13.

5. V. Gunasekar, D. Gowdhaman, V. Ponnusami. 2013 Biodegradation Of Reactive Red M5B Dye Using Bacillus subtilis. International Journal of ChemTech Research 5(1), 131-135.

6. Francis Hassard, Jeremy Biddle, Richard Harnett, Tom Stephenso. 2018 Microbial extracellular enzyme activity affects performance in a full-scale modified activated sludge process. Science of the Total Environment 625 , $1527-1534$.

7. Xuelian Li, Juan Zhang, Yucheng Jiang, Mancheng Hu, Shuni Li, and Quanguo Zhai. 2013 Highly Efficient Biodecolorization/Degradation of Congo Red and Alizarin Yellow R by Chloroperoxidase from Caldariomyces fumago: Catalytic Mechanism and Degradation Pathway. Ind. Eng. Chem. Res 52 (38), 13572-13579.

8. Y. S. Ma, S. T. Huang, and J. G. Lin. 2000 Degradation of 4-nitrophenol using the Fenton process. Water Science and Technology 42(3), 1155-160.

9. H. Zangeneh, A. A. L. Zinatizadeh, M. Habibi, M. Akia, M. Hasnain Isa. 2015 Photocatalytic oxidation of organic dyes and pollutants in wastewater using different modified titanium dioxides: A comparative review. Journal of Industrial and Engineering Chemistry 26, 1-36.

10. G. Colon, J. M. Sanchez-Espa na, M.C. Hidalgo, J.A. Nav`ı. 2006 Effect of TiO2 acidic pre-treatment on the photocatalytic properties for phenol degradation. J. Photobiol. A: Chem. 179, 20-27.

11. M.C. Hidalgo, M. Maicu, J.A. Navío, G. Colo' n. 2007 Photocatalytic properties of surface modified platinised TiO2: effects of particle size and structural composition. Catal. Today 129, 43-49. 
12. A. Özlem Yıldırım, Şermin Gül, Orkide Eren, Erdal Kuşvuran. 2011 A Comparative Study of Ozonation, Homogeneous Catalytic Ozonation, and Photocatalytic Ozonation for C.I. Reactive Red 194 Azo Dye Degradation. Clean Soil Air Water 39(8) 795-805.

13. O. Chedeville, M. Debacq, M. Ferrante Almanza, C. Porte. 2007 Use of an ejector for phenol containing water treatment by ozonation, Sep. Purif. Technol. 57, 201-208.

14. A Bhankhar, M Giri, K Yadav and N Jaggi. 2014 Study on degradation of methyl orange-an azo dye by silver nanoparticles using UV-Visible spectroscopy. Indian J Phys 88(11), 1191-1196.

15. Yingying Sha, Iswarya Mathew, Qingzhou Cui, Molly Clay, Fan Gao, Xiaoqi Jackie Zhang, Zhiyong Gu. 2016 Rapid degradation of azo dyemethyl orange using hollow cobalt nanoparticles. Chemosphere 144, 1530-1535.

16. Shenghui Xie, Ping Huang, Jamie J. Kruzic, Xierong Zeng \& Haixia Qian. 2016 A highly efficient degradation mechanism of methyl orange using Fe-based metallic glass powders. Scientific Reports 6, 1-10.

17. Kumari Jyoti, Ajeet Singh. 2016 Green synthesis of nanostructured silver particles and their catalytic application in dye degradation, Journal of Genetic Engineering and Biotechnology 14(2), 311-317.

18. Hosam I. Salaheldin. 2017 Rapid Microwave Synthesis of Silver Nanoparticles Capped by Soluble Starch and Its Catalytic Activity. Journal of Bionanoscience 11, 1-9.

19. Hosam I Salaheldin 2017 Comparative catalytic reduction of 4-nitrophenol by polyacrylamide-gold nanocomposite synthesized by hydrothermal autoclaving and conventional heating routes. Adv. Nat. Sci.: Nanosci. Nanotechnol. 8, 045001-045010.

20. Bhagavanth Reddy Ganapuram, Madhusudhan Alle, Ramakrishna Dadigala, Ayodhya Dasari, Venkatesham Maragoni, Veerabhadram Guttena. 2015 Catalytic reduction of methylene blue and Congo red dyes using green synthesized gold nanoparticles capped by salmalia malabarica gum. Int Nano Lett 5, 215-222.

21. Xiaoqing Chen, Zhansheng Wu, Dandan Liu and Zhenzhen Gao 2017 Preparation of ZnO Photocatalyst for the Efficient and Rapid Photocatalytic Degradation of Azo Dyes. Nanoscale Research Letters 12, 143-153.

22. Pranjal Saikia, Abu T Miah and Partha P Das. 2017 Highly efficient catalytic reductive degradation of various organic dyes by Au/CeO2-TiO2 nano-hybrid. J. Chem. Sci. Vol. 129(1), 81-93.

23. Marguerite Rinaudo. 2006 Chitin and chitosan: Properties and applications. Prog. Polym. Sci. 31, 603-632

24. Suneeta Kumari, Pradip Kumar Rath. 2014 Extraction and Characterization of Chitin and Chitosan from (Labeorohit) Fish Scales, Procedia Materials Science 6, 482 - 489.

25. Vida Zargar, Morteza Asghari, Amir Dashti. 2015 A Review on Chitin and Chitosan Polymers: Structure, Chemistry, Solubility, Derivatives, and Applications. Chem Bio Eng Rev 2(3), 204-226

26. Mehrez E. El-Naggar, Tharwat I. Shaheen, Moustafa M.G. Fouda, Ali A. Hebeish. 2016 Eco-friendly microwaveassisted green and rapid synthesis of well-stabilized gold and core-shell silver-gold nanoparticles. Carbohydrate Polymers 136, 1128-1136.

27. Seung Kwon Seol, Daeho Kim, Sunshin Jung, Yeukuang Hwu 2011 Microwave synthesis of gold nanoparticles: Effect of applied microwave power and solution pH. Materials Chemistry and Physics 131, 331-335.

28. Vo Ke Thanh Ngo, Hoang Phuong Uyen Nguyen, Trong Phat Huynh, Nguyen Nguyen Pham Tran, Quang Vinh Lam and Thanh Dat Huynh. 2015 Preparation of gold nanoparticles by microwave heating and application of spectroscopy to study conjugate of gold nanoparticles with antibody E. coli O157:H7, Adv. Nat. Sci.: Nanosci. Nanotechnol. 6, 035015-035021. 
29. Seung Kwon Seol, Daeho Kim, Sunshin Jung, Won Suk Chang, and Ji Tae Kim. 2013 One-Step Synthesis of PEG-Coated Gold Nanoparticles by Rapid Microwave Heating, Journal of Nanomaterials. 2013, 531760531766,.

30. Vo Ke Thanh Ngo, Dang Giang Nguyen, Trong Phat Huynh and Quang Vinh Lam. 2016 A low cost technique for synthesis of gold nanoparticles using microwave heating and its application in signal amplification for detecting Escherichia Coli O157:H7 bacteria. Adv. Nat. Sci.: Nanosci. Nanotechnol. 7, 035016-035025.

31. Majid Darroudi, Mansor B. Ahmad, Mohammad Hakimi, Reza Zamiri, Ali Khorsand Zak, Hasan Ali Hosseini, and Mohsen Zargar. 2013 preparation, characterization, and antibacterial activity from $\gamma$-irradiation silver nanoparticles in aqueous gelatin. International Journal of Minerals, Metallurgy and Materials 20(4), 403-409.

32. Huang H, Yang X. 2004 Synthesis of polysaccharide-stabilized gold and silver nanoparticles: a green method. Carbohydr Res. 339(15), 2627-31.

33. Lung-Shuo Wang, Chih-Yu Wang, Chih-Hui Yang, Chen-Ling Hsieh, Szu-Yu Chen, Chi-Yen Shen, Jia-Jung Wang, and Keng-Shiang Huang. 2015 Synthesis and anti-fungal effect of silver nanoparticles-chitosan composite particles. International Journal of Nanomedicine 10, 2685-2696.

34. Mervat F. Zayeda, Wael H. Eisa. 2014 Phoenix dactylifera L. leaf extract phytosynthesized gold nanoparticles; controlled synthesis and catalytic activity. Spectrochimica Acta Part A: Molecular and Biomolecular Spectroscopy 121(5), 238-244.

35. Mervat F.Zayed, Wael H.Eisa, Yasser K.Abdel-Moneam, Salah M.El-kousy, and Ahmed Atia. 2015 Ziziphus spina-christi based bio-synthesis of Ag nanoparticles. Journal of Industrial and Engineering Chemistry 23(25), 50-56.

36. Yinbo Peng, Chenlu Song, Chuanfeng Yang, Qige Guo, Min Yao. 2017 Low molecular weight chitosan-coated silver nanoparticles are effective for the treatment of MRSA-infected wounds. International Journal of Nanomedicine12, 295-304.

37. Youling Yuan, Betsy M. Chesnutt, Warren O. Haggard and Joel D. Bumgardner. 2011 Deacetylation of Chitosan: Material Characterization and in vitro Evaluation via Albumin Adsorption and Pre-Osteoblastic Cell Cultures, Materials 4, 1399-1416.

38. Alaeddine Kibeche, Alexandre Dionne, Roxanne Brion-Roby, Christian Gagnon and Jonathan Gagnon. 2015 Simple and green technique for sequestration and concentration of silver nanoparticles by polysaccharides immobilized on glass beads in aqueous media. Chemistry Central Journal 9, 34-43.

39. Anna Regiel-Futyra, Małgorzata Kus-Lisk iewicz, Victor Sebastian, Silvia Irusta, Manuel Arruebo, Grażyna Stochel, and Agnieszka Kyzio. 2015 Development of Noncytotoxic Chitosan-Gold Nanocomposites as Efficient Antibacterial Materials, ACS Appl. Mater. Interfaces. 7, 1087-1099.

40. Tanja Jurkin \& Martina Guliš \& Goran Dražić \& Marijan Gotić, 2016 Synthesis of gold nanoparticles under highly oxidizing conditions. Gold Bull. 49, 21-33.

41. Sivalingam Ramesh, Heung Soo Kim, Young-Jun Lee, Gwang-Wook Hong and Joo-Hyung Kim. 2017 Nanostructured Silica/Gold-Cellulose- Bonded Amino-POSS Hybrid Composite via Sol-Gel Process and Its Properties. Nanoscale Research Letters 12, 381-394.

42. Sadanand Pandey, Gopal K. Goswami, Karuna K. Nanda. 2013 Green synthesis of polysaccharide/gold nanoparticle nanocomposite: An efficient ammonia sensor. Carbohydrate Polymers 94, 229-234. 
43. Emanuela Filippo, Antonio Serra, Alessandro Buccolieri, Daniela Manno. 2010 Green synthesis of silver nanoparticles with sucrose and maltose: Morphological and structural characterization. Journal of NonCrystalline Solids 356, 344-350.

44. Pani A, Lee J H, Yun SI. 2016 Autoclave mediated one-pot-one-minute synthesis of AgNPs and Au-Ag nanocomposite from Melia azedarach bark extract with antimicrobial activity against food pathogens. Chem Cent J. 31, 10-15.

45. S. Mosleh, M.R. Rahimi, M. Ghaedi, K. Dashtian, S. Hajati, and S. Wang. 2017 Ag3PO4/AgBr/Ag-HKUST-1-MOF composites as novel blue LED light active photocatalyst for enhanced degradation of ternary mixture of dyes in a rotating packed bed reactor. Chemical Engineering and Processing 114, 24-38.

46. Na Li, María Echeverría, Sergio Moya, Jaime Ruiz, and Didier Astruc. 2014 "Click"Synthesis of Nona-PEGbranched Triazole Dendrimers and Stabilization of Gold Nanoparticles That Efficiently Catalyze p- Nitrophenol Reduction, Inorg. Chem. 53, 6954-6961.

47. Abilash Gangula, Ramakrishna Podila, Ramakrishna M, Lohith Karanam, Chelli Janardhana, and Apparao M. Rao. 2011 Catalytic Reduction of 4-Nitrophenol using Biogenic Gold and Silver Nanoparticles Derived from Breynia rhamnoides. Langmuir 27 (24), 15268-15274

48. Nadia A. Youssef, Seham A. Shaban, Fatma A. Ibrahim, Aya S. Mahmoud. 2016 Degradation of methyl orange using Fenton catalytic reaction. Egyptian Journal of Petroleum 25, 317-321. 